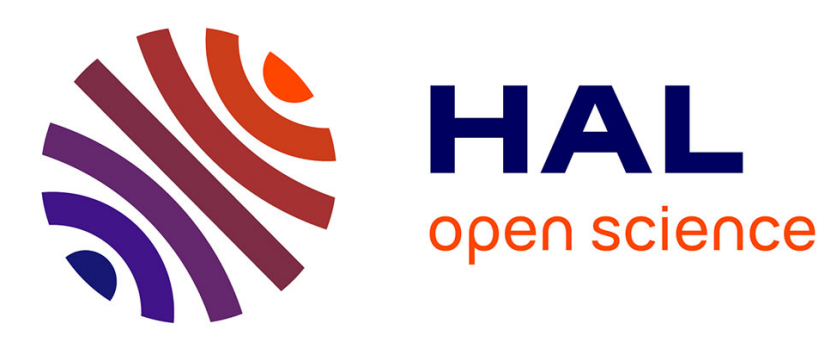

\title{
Maps of Dispersions for Machining Processes
}

Valéry Wolff, Arnaud Lefebvre, Jean Renaud

\section{To cite this version:}

Valéry Wolff, Arnaud Lefebvre, Jean Renaud. Maps of Dispersions for Machining Processes. Concurrent Engineering: Research and Applications, 2006, 14 (2), pp.129-139. 10.1177/1063293X06066196 . hal-00571191

\section{HAL Id: hal-00571191 \\ https://hal.science/hal-00571191}

Submitted on 1 Mar 2011

HAL is a multi-disciplinary open access archive for the deposit and dissemination of scientific research documents, whether they are published or not. The documents may come from teaching and research institutions in France or abroad, or from public or private research centers.
L'archive ouverte pluridisciplinaire HAL, est destinée au dépôt et à la diffusion de documents scientifiques de niveau recherche, publiés ou non, émanant des établissements d'enseignement et de recherche français ou étrangers, des laboratoires publics ou privés. 


\title{
Maps of Dispersions for Machining Processes
}

\author{
Valéry Wolff, ${ }^{1, *}$ Arnaud Lefebvre ${ }^{2}$ and Jean Renaud ${ }^{3}$ \\ ${ }^{1}$ Claude Bernard Université - Lyon 1, IUT B, Mechanical Engineering Department \\ 17 rue de France, 69627 Villeurbanne Cedex, France \\ ${ }^{2} P R I S M a$ Laboratory - Lyon 1, 43 bd du 11 novembre 1918 \\ 69622 Villeurbanne Cedex, France \\ ${ }^{3} R G I P$, Research Group on Innovation Process \\ 8 rue Bastien Lepage, 54360 Nancy Cedex, France
}

\begin{abstract}
During product design, the design office defines dimensional and geometrical parameters according to the use criteria and product functionality. The manufacturing department must integrate the manufacturing and the workpiece position dispersions during the choice of tools and the machine operating modes and parameter values to respect the functional constraints. In this article, the authors suggest a model for the turning dispersions taking into account not only geometrical specifications of position or orientation, but also the experience of method actors. A representation using the principle of know-how maps in two or three dimensions is privileged. The most interesting aspect is that these maps include tacit and explicit knowledge. An experimental study realized on a machine tool (HES 300) allows one to elaborate knowledge maps especially for the turning process.
\end{abstract}

Key Words: knowledge capitalization, know-how maps, machining dispersions, tolerancing and dimensioning.

\section{Introduction}

In a strong competition context, companies realize that their knowledge and know-how constitute an important competitive advantage. In product design and manufacturing processes, many companies show an interest saving and using the operators and the industrial experience of experts. This shows an interest by having expert knowledge ready to use at all times [1-3].

Usually, experience is described as being made up of two components [4]:

- Explicit knowledge is the type of knowledge that an individual has acquired mainly in school and university. Explicit knowledge implies factual information such as material properties, technical information, and tool characteristics. Thus explicit knowledge is expressed in words and numbers and is therefore easily communicated and shared [5]. This knowledge is objective or unbiased.
*Author to whom correspondence should be addressed.

E-mail: valery.wolff@iutb.univ-lyonl.fr
- Tacit knowledge is highly personal and hard to communicate or to share with others. Tacit knowledge is deeply rooted in individual experience and it consists in belief and perceptions stored deep in the worldview of an individual that are taken for granted [6]. Tacit knowledge equals practical know-how. This knowledge is mostly subjective.

The extraction of this kind of knowledge, called 'expert knowledge' [7,8], is not easy. 'Expert knowledge' can be defined as the knowledge that integrates not only the theoretical knowledge based on known scientific or technical principles but also that based on the expert's choice-making mechanisms or behavior as well as the decision-making environment, which is a fundamental factor when capitalizing on an expertise. Experience is practical and not theoretical. Some methods and models are necessary to extract and formalize the knowledge.

These two components of knowledge require effective and additional methods. A generic approach to knowledge capitalization is made up of three integrated phases: locating and extracting knowledge, modeling, and using models.

- The first phase comprises identification and extraction of tacit knowledge from the product or process design according to the decision-maker's point of view. 
This involves taking measurements within the framework of an experimental strategy. This extraction of knowledge is followed by a proposition to structure the knowledge in order to understand and to model it. Measurements can be evaluated by an appropriate tool or by an expert. In both cases they are called experimental data $[9,10]$.

- The second phase consists of modeling knowledge and confirming it. This phase involves choosing a model (a knowledge model, a behavioral one, or a hybrid) in accordance with the phenomenon being studied. The structure of the chosen model must be adapted to its function or use, but the choice remains a human responsibility. Once the model has been chosen, its parameters can be adjusted by an expert or by identification using experimental data. The validation of the model will guarantee its relevance and accuracy before it is used [11,12].

- The third phase consists of using 'ready to use' knowledge. It is important to structure knowledge to reuse it. The aim is to obtain operational and longlasting models [13-15].

\section{Capitalization and Cartography of the Expert Knowledge}

\subsection{Methods of Capitalization}

Several methods of capitalization exist and can be applied to build a company memory. These methods are based on the return of experiences. The commonly used methods are:

- The MKSM (Methodology for Knowledge System Management) Method. Knowledge is modeled according to three dimensions: information, signification, and context of study. Every dimension is composed of data processing, activity of the domain, and tasks. This method allows one to describe knowledge and to manage it [16].

- The REX Method allows one to extract elements of experiences from activities and to restore them in an objective of knowledge reuse. Originally, this type of approach was applied specifically to high-risk environments such as nuclear thermal power stations [17-19].

- The MEREX Method consists of consideration of positive and negative experiences from innovations and the return of experiences during the design of new products [20].

The authors propose another approach to knowledge capitalization by know-how maps, introduced by ERPI and PRISMa laboratories. The interest of these know-how maps is to take into account the tacit and explicit knowledge of an expert. The aim is to re-use knowledge during the design process for any new product. These maps become of real help in the decision-making process.

\subsection{Know-how Maps}

The benefits of know-how maps lie in the graphic representation of the 'expert knowledge' and the possibility of proposing different areas of technical feasibility described according to known variations for several parameters. These maps also allow taking into account the processes of expert reasoning represented as areas of interest according to the studied industrial priorities. Finally, they propose a traceability of product/process knowledge and a transmission of this knowledge among the various experts during time [21].

The methodology brings another methodological answer to compare with the cognitive map [22-24]. The objective of these cognitive maps is to represent the structure of the causal assertions of a person. The concept of modeling the cognitive process comes from psychology $[25,26]$. Cognitive maps allow one to model, in graphic representation, the knowledge of an individual or a group concerning a particular object. Langfield-Smith underlines that a cognitive map is not a durable structure $[27,28]$. It corresponds to a passing collective cognition. Cognitive maps are usually derived through interviews and are, therefore, intended to represent the subjective world of the interviewee. Cognitive mapping is a formal modeling technique with rules for its development. Knowledge is not data or a fact. Rather it represents a network of information related to an object as shown in Table 1. The authors suggest a comparison between the two concepts of cognitive maps.

In the next section the principle of know-how maps concerning a study of dispersions related to a turning manufacturing process is presented.

\subsection{Know-how Maps Applied to Expert Knowledge}

The principle of know-how maps consists in formalizing knowledge 'ready to use' into a graphical model in a concurrent engineering context. A know-how map describes a set of expert knowledge (from the design to manufacturing processes) and is represented in a graphical form. The construction of these know-how maps includes three main stages: extraction, modeling, and using knowledge. This study aims at showing at the ' $t$ ' moment the expertise of one or several individuals for a given environment and a given activity or an operational task. This involves managing the individual 
Table 1. Comparison enters the cognitive charts and maps of know-how.

\begin{tabular}{|c|c|c|}
\hline & Cognitive map & Know-how map \\
\hline \multirow[t]{3}{*}{ Convergent points } & Physical support. Visual charts & \\
\hline & $\begin{array}{l}\text { Builds itself partly or entirely starting } \\
\text { from the cognition of the expert }\end{array}$ & \\
\hline & Integration of fuzzy or related logic & \\
\hline \multirow[t]{3}{*}{ Divergent points } & Networks (arcs and nodes) & Zone preferably \\
\hline & Tacit knowledge & Taking into account of explicit and tacit knowledge \\
\hline & Determinist & Choice is left to the expert \\
\hline Advantages & Use and easy comprehension of the charts & Easy construction of tacit knowledge \\
\hline \multirow[t]{2}{*}{ Disadvantages } & $\begin{array}{l}\text { Difficult to represent } \\
\text { Complex graphs }\end{array}$ & The representation remains to two or three dimensions \\
\hline & $\begin{array}{l}\text { Need for carrying out several front intermediate } \\
\text { graphs to obtain the final graph }\end{array}$ & Seek mathematical models for explicit knowledge \\
\hline
\end{tabular}

knowledge of the decision maker in order to formalize it and use it in a collective way. Expert knowledge is extracted and structured, modeled, and applied to improve the design process. Some authors have focused on knowledge capitalization at the intersection between two disciplines: knowledge engineering and human management. The knowledge map remains incomplete. It corresponds to the representation of a field of activity according to the point of view of the experts. The know-how maps include two types of knowledge [29]:

- Objective knowledge or knowledge engineering. Knowledge is general, and it is not connected to a precise problem. It is relative to the function of a system and to the causal relations between the system variables. Explicit knowledge is represented by mathematical models.

- Subjective knowledge or tacit knowledge. This knowledge is formalized by heuristic forms which reflect the experience of the experts. They are specific in the treated problem and the expert who designed the system. Expert's rules or reasoning schemes are often used in these maps.

Identifying an expert remains a difficult task. Shanteau [30] proposed nine experts' levels (experience, certification, social cheer, consistency reliability, consensus reliability, discrimination, behavioral characteristics, knowledge testing and expert creation). He also proposed a tool to estimate an expert according to indications of discrimination (large variety) and logic (repetition).

The methodology of know-how maps consists of representing under a 2D graph, a response function depending on continuous parameters. The three main steps of modeling are:

1. Identification of knowledge: this step consists of identifying various product/process parameters of the studied system.
2. Modeling explicit knowledge and tacit knowledge: the map construction includes three parts:

- The first part aims at determining the equation of regression obtained, for example, by a design of experiments.

- The second part aims at the research of feasibility areas according to the expert's knowledge.

- The third step gives production rules depending on the various working areas.

3. Use of the know-how maps: the know-how maps are used during the product/process design.

Figures 1 and 2 show an example of know-how maps construction, which represents the evolution of a process parameter $P_{\mathrm{k}}$ (number of manufacturing operations) according to two products parameters $P_{i}$ and $P_{j}$. Feasibility areas 1 and 2 (Figure 1) are defined by a mathematical model (explicit knowledge). According to the expert knowledge, a third area is defined (Figure 2). Three areas are then defined, which correspond to manufacturing operations for a given manufacturing feature.

\subsection{Benefit of Know-how Maps}

The know-how mapping presented in this article is a methodological tool to collect the information and knowledge of experts' minds. This tool allows one to propose 'ready to use' knowledge for the industrial decision-maker. The representation of knowledge as know-how maps presents several interests:

- It allows one to include practices and experiences of the experts and make them understandable [31,32].

- It allows one to take into account processes of reasoning and thought of experts under feasibility areas according to the studied industrial priorities.

- It can be used for educational finality. It becomes a support in the discussion and exchange among experts. The know-how maps become a tool of visual 


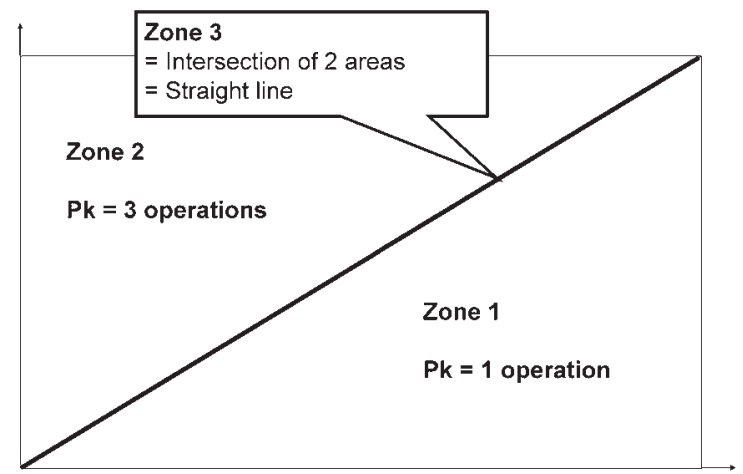

Figure 1. Know-how maps for explicit knowledge obtained with a mathematical model. Number of operations $\left(P_{\mathrm{k}}\right)$ necessary for a manufacturing feature represented with two areas.

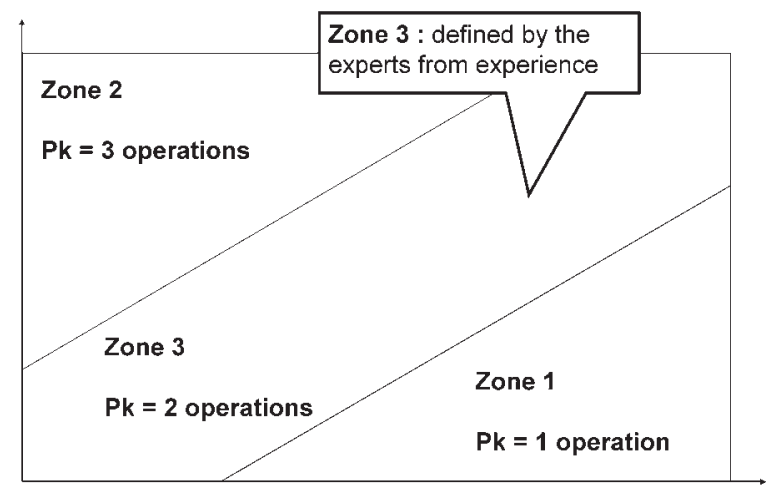

Figure 2. Know-how maps with tacit knowledge added by the experts. Expert's knowledge allows the building of the third area.

communication, a real practical guide for the decision-maker.

- It allows one to assure the transmission of knowledge among the various experts during time.

- It allows one to integrate objective and subjective knowledge on the same graphic support.

- Finally, it allows an update of the expertise according to the evolution of products and used practices.

However, the know-how map remains partial and needs an expert's rules to improve the model. The map must correspond to a knowledge representation according to the expert's point of view.

\subsection{Industrial Applications}

Knowledge representation in the form of know-how maps using recommendations responds to a strong demand from people involved in design and manufacturing. Map construction depends on the point of view of the specialist who is in charge of its elaboration. But these maps have to be generic enough to represent the product and associated processes in the concurrent engineering context.

Several industrial studies about elaboration of know-how maps have been achieved around different manufacturing contexts for the past 10 years: food supplying industry, halogen lamps manufacturing within the Philips Company [33], and camshaft bearing lines machining on five axis centers [7] within the Renault company.

In the next section, an application of the know-how maps to study the manufacturing dispersions related to a turning process is presented.

\section{Know-how Maps Applied to Machining Dispersions in Turning}

The objective of this third part consists in developing the design process of know-how maps starting from a study of machining dispersions. The evaluation of dispersions allows the development of know-how maps related to a type of machine-tool and a standard part fixture.

Calculations of manufacturing dimensions starting from the geometrical definition of the part can be generally obtained from two methods [34,35]: the installation of chains of dimensions or the method of dispersions. It is this second method which is adopted in this study.

\subsection{Dispersions Modeling}

The authors call machining dispersions $[3,41]$ the geometrical and dimensional variations obtained on a series of real parts for a manufacturing process and a given machine-tool. The supposed sources of dispersions have several origins, in particular, related to controls with the inflexion of the tools, the cutting efforts, and the geometrical defects of the machine tool. The rule which characterizes each origin of dispersions can be of various mathematical models (Normal or Poisson distribution, etc.); nevertheless the assumption is made that the resultant response follows a Normal distribution [36].

The industrial need is to control each machine according to its machining dispersions in time. The model proposed here can fit to a range of machine-tool (e.g., turning, milling, etc.) but each machine has its own characteristics and then its own dispersion values.

Machine characteristics (slides clearance, drive systems, etc.) for a given machining operation can vary in time. Thanks to the limited numbers proposed by the model, it is possible to update periodically the dispersion values and then to optimize the manufacturing process. 


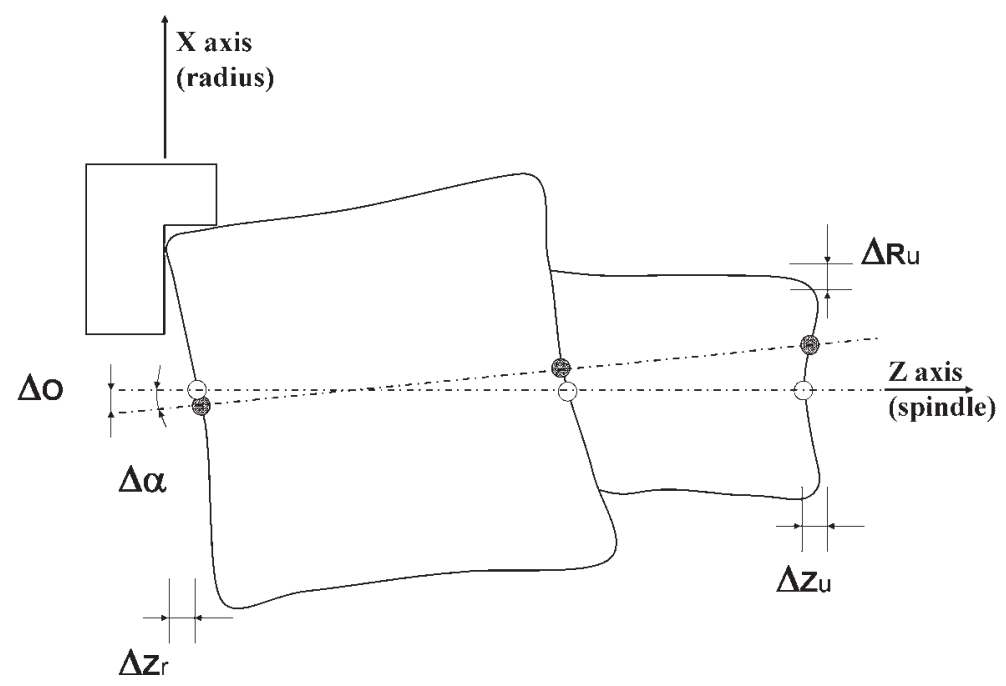

Figure 3. Modeling of the 5 dispersions retained in turning.

\subsubsection{EXTENDED PROPOSED MODEL}

Considering a shouldered part, the modeling of the behavior of a lathe is classically approached according to a thorough study of five parameters of dispersions $\left(\Delta_{\text {machine }}\right)$ as shown in the Figure 3 . These dispersions are classified into two categories: the first relates to dispersions of setting in position (re-machining) such as $\Delta \mathrm{O}, \Delta \alpha, \Delta Z_{\mathrm{r}}$. The second category includes machining dispersions like $\Delta R_{\mathrm{u}}$ (dispersion of machining according to $\mathrm{X}$-axis) and $\Delta Z_{\mathrm{u}}$ (dispersion of machining according to the Z-axis: spindle axis).

For the taking into account of the axial dimensions and the dispersions obtained during machining, the traditional method of $\Delta L$ is used on $\mathrm{X}$ and $\mathrm{Z}$-axes. The parameters are then indicated by $\Delta Z_{\mathrm{u}}, \Delta R_{\mathrm{u}}, \Delta Z_{\mathrm{r}}$. Consideration of the geometrical specifications [37] (coaxiality, perpendicularity, etc.) involves the use of new parameters $\Delta \alpha$ and $\Delta \mathrm{O}$.

- $\Delta \alpha$ represents the angular remachining error of the part in the soft jaws in turning,

$-\Delta \mathrm{O}$ is the defect of concentricity (between the axis of the reference surface and the spindle axis) located at the bottom of the soft jaws,

- $\Delta Z_{\mathrm{r}}$ corresponds to the axial remachining error of the part in the part holder along the $\mathrm{Z}$-axis.

The objective of the proposed model is to determine the relationships between the machine-tool parameters and the product/process parameters.

These relations are of the type:

$$
\Delta_{\text {machine }}=f_{i}\left(p_{i}\right)
$$

where $\Delta_{\text {machine }}$ is one of five dispersions and $p_{i}$ a set of parameters (discrete or continuous).

\subsubsection{DIMENSIONING ACCORDING TO ISO STANDARDS}

ISO standards of dimensioning and tolerancing, gathered under the term of GPS (geometrical specification of the products) provide a complete language to mechanical engineers. They are adopted today by the manufacturing industry. The geometrical model of dispersions in the simulation of machining which is proposed takes these three-dimensional specifications into account.

For example, in the case of coaxiality, the methods of calculation necessary to connect the model parameters to ISO specifications are defined.

Coaxiality relates to the relative position of the real axis of the specified surface and the reference/datum axis. It does not relate to surfaces but always relates to axes. The definition resulting from the standard and its interpretation is defined in Figure 4.

This definition must be interpreted and calculated to make the obtained measurement on the coordinate measuring machine $(\mathrm{CMM})$ correspond with the part design specifications.

\subsection{Representation of the Dispersions Model: Maps from Experimental Design}

The authors now propose to extend the field of application of the model. It must take into account the variations of certain parameters of the manufacturing process, which are likely to involve variations of dispersions. The method of the experimental design is exploited here to quantify the influence of these modifications on dispersions.

To quantify the relations $f_{i}$ between the dispersions and product/process parameters, the design of experiments methodology is used [38-40]. Indeed, the 


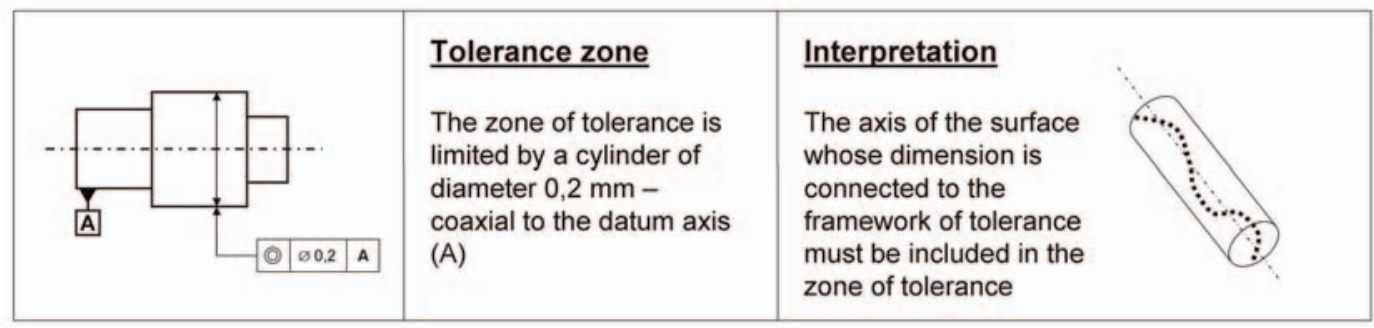

Figure 4. GPS standards - coaxiality according to ISO 8015.

knowledge described by the $f_{i}$ functions comes under the tacit and behavioral field of major knowledge. The design of experiments as well as the general models of linear regressions is well adapted to the determination of the $f_{\mathrm{i}}$ functions.

The maps of dispersions related to expert knowledge are called a chart of a dispersion function $y=f\left(x_{i}\right)$ into two or three dimensions, according to product or process parameters resulting from a formal modeling. In order to use these maps of dispersions in a predictive mode, a representation must be obtained in two dimensions, in which the model contains a maximum of two continuous parameters among the $x_{i}$.

For each combination of discrete parameters, two continuous parameters $x_{1}$ and $x_{2}$ are varied simultaneously into a range of variation specified by the experts. Then, the theoretical response is calculated. Each function is represented for a combination of discrete parameters. Moreover, for correct use, criteria of use is added on the know-how maps.

\subsection{Experimental Protocol}

\subsubsection{EXPERIMENTAL PARAMETERS}

Five product/process parameters have been defined to evaluate various dispersions. Table 2 gives the list of the parameters. Some particular interactions are taken into account (see Table 3).

\subsubsection{DESIGN OF EXPERIMENTS}

Taguchi's method is chosen to limit the number of tests to take into account the times of machining and control. Taking into account the criterion of orthogonality and number of degrees of freedom, the $\mathrm{L}_{16}\left(2^{15}\right)$ table was selected. For each response of the studied dispersion, the order of the tests as well as the combinations of the parameters are given in Table 4 .

\subsection{Experimental Results}

\subsubsection{EVALUATION OF RESPONSES}

Responses of the experiments are obtained by measurements that allow calculation of the dispersion parameters $\Delta \mathrm{O}, \Delta \alpha, \Delta R_{\mathrm{u}}, \Delta Z_{\mathrm{r}}$, and
Table 2. Factors and associated values.

\begin{tabular}{lcccc}
\hline Parameters & & Type & \multicolumn{2}{c}{ Values } \\
\hline Insert type & $\mathrm{N}$ & discrete & $\mathrm{P} 15$ & $\mathrm{P} 35$ \\
Nose radius $(\mathrm{mm})$ & $R_{\varepsilon}$ & discrete & 0.40 & 0.80 \\
Cutting speed $(\mathrm{m} / \mathrm{min})$ & $V_{\mathrm{c}}$ & continuous & 150 & 280 \\
Material of the machined part & $M$ & discrete & $\mathrm{A} 60$ & XC38 \\
Feed rate (mm/turn) & $F$ & continuous & 0.10 & 0.30 \\
\hline
\end{tabular}

Table 3. Interactions retained between the parameters by the experts.

\begin{tabular}{lc}
\hline Interactions & \\
\hline Insert type - cutting speed $(\mathrm{m} / \mathrm{min})$ & $\mathrm{NV}$ \\
Material - feed rate $(\mathrm{mm} / \mathrm{turn})$ & $\mathrm{Mf}$ \\
Cutting speed (m/min) - material & $\mathrm{V}_{\mathrm{c}} \mathrm{M}$ \\
Insert type - feed rate (mm/turn) & $\mathrm{Nf}$ \\
\hline
\end{tabular}

Table 4. Table of the experiments (extract).

\begin{tabular}{cccccc}
\hline & $\begin{array}{c}\text { Insert } \\
\text { type }\end{array}$ & $\begin{array}{c}\text { Nose } \\
\text { radius } \\
\boldsymbol{R}_{\varepsilon}(\mathbf{m m})\end{array}$ & $\begin{array}{c}\text { Cutting } \\
\text { speed } \boldsymbol{V}_{\mathbf{c}}(\mathbf{m} / \mathbf{m i n})\end{array}$ & $\begin{array}{c}\text { Material } \\
\boldsymbol{M}\end{array}$ & $\begin{array}{c}\text { Feed } \\
\text { rate } \boldsymbol{f} \\
(\mathbf{m m} / \text { turn })\end{array}$ \\
\hline 1 & $\mathrm{P} 15$ & 0.4 & 150 & $\mathrm{~A} 60$ & 0.1 \\
2 & $\mathrm{P} 15$ & 0.4 & 150 & XC38 & 0.3 \\
3 & $\mathrm{P} 15$ & 0.4 & 280 & $\mathrm{~A} 60$ & 0.3 \\
$\ldots$ & $\ldots$ & $\ldots$ & $\ldots$ & $\ldots$ & $\ldots$ \\
16 & $\mathrm{P} 35$ & 0.8 & 280 & XC38 & 0.1 \\
\hline
\end{tabular}

$\Delta Z_{\mathrm{u}}$ (in millimeters). A reduced sample of five workpieces is sufficient. Taguchi's method used is a standard $\mathrm{L}_{16}\left(2^{15}\right)$ experiment, which is repeated five times.

Two cases were observed. The response is calculable starting from the standard deviation obtained by the measurement of one or several dimensions:

1. Case of the response obtained by the measurement of only one dimension: This relates to dispersions $\Delta \mathrm{O}$, $\Delta \alpha, \Delta R_{\mathrm{u}}$. For example, the relation relating to $\Delta R_{\mathrm{u}}$ is written: 


$$
\Delta R_{\mathrm{u}}=\left[\frac{6 \times\left(\sigma_{\text {diametral }}\right)_{\text {sample }}}{C_{4}}\right] / 2
$$

where $C_{4}$ is the weighting taken in the statistical table of the reduced samples.

2. Case of the response obtained by the measurement of several dimensions $d_{i}$ (standard deviation noted $\sigma_{i}$ ): The variance of required dispersion is related to the sum of the variances of the concerned dimensions. This relates to $\Delta Z_{\mathrm{r}}$ dispersions (or $\Delta Z_{\mathrm{u}}$ ). The relations used are as follows:

and thus

$$
\sigma_{\mathrm{r}}=\frac{\sqrt{\sum \pm \sigma_{i}^{2}}}{\sqrt{2}}
$$

$$
\Delta Z_{\mathrm{r}}=\frac{\left(\sigma_{\mathrm{r}}\right)_{\text {sample }}}{C_{4}} \times 6
$$

The values necessary to calculate the dispersion parameters (part diameters, points of intersection, etc.) are measured directly on the 80 parts using a coordinate measuring machine. Some of these values are only intermediate parameters.

Each batch of five parts allows one to calculate the standard deviation of each answer $\Delta Z_{\mathrm{r}}, \Delta \mathrm{O}, \Delta \alpha, \Delta R_{\mathrm{u}}$, and $\Delta Z_{\mathrm{u}}$ using CMM measurements. The design of experiments provides in this way 16 values for each studied response.

\subsubsection{ANALYSIS AND SUMMARY OF THE RESULTS OBTAINED}

The analysis of the measurements obtained has been carried out on the 80 parts of the $\mathrm{L}_{16}\left(2^{15}\right)$ plan defined previously to determine the parameters of the manufacturing process, planning and influencing dispersions of machining.

The variance analysis indicates that a parameter is statistically significant on the response as soon as the parameter $p$ is higher than 0.05 (level of confidence higher than $95 \%$ ).

The regression coefficient $\left(R^{2}\right)$ makes it possible to evaluate the percentage of data explained by the model. The higher the $R^{2}$ is, the more the model is usable in a predictive mode. A coefficient of $R^{2}$ between $\sim 70$ and $\sim 90 \%$ corresponds to an acceptable model.

Table 5 presents the synthesis of the Pareto chart associated with the dispersions obtained by experimentation. For each answer studied $\left(\Delta Z_{\mathrm{r}}, \Delta \mathrm{O}\right.$, $\Delta \alpha, \Delta R_{\mathrm{u}}$, and $\Delta Z_{\mathrm{u}}$ ), the diagram highlights the influence (significant or not) of the various parameters of the design of experiments on the studied response.

\subsection{Know-how Mapping for the $\Delta R_{\mathrm{u}}$ Response}

\subsubsection{MAP CONSTRUCTION}

The authors choose to develop an example of map related to the response of $\Delta R_{\mathrm{u}}$ dispersion, which corresponds to the machining dispersion according to $\mathrm{X}$-axis.

In this study, the $f_{i}$ function to be represented as a chart of dispersion is thus:

$$
\begin{gathered}
\Delta R_{\mathrm{u}}=f(\text { insert type }, \text { nose radius, material }, \\
\text { cutting speed }, \text { feedrate })
\end{gathered}
$$

The linear model of regression is present in the form of:

$$
\begin{aligned}
\Delta R_{\mathrm{u}}= & \alpha+\beta N+\chi R_{\varepsilon}+\delta V_{\mathrm{c}}+\varepsilon M+\phi f \\
& +\gamma N V-\eta N f-\varphi V_{\mathrm{c}} M+\kappa M f
\end{aligned}
$$

where the coefficients are:

\begin{tabular}{llllllllll}
\hline$\alpha$ & 0.02789 & $\beta$ & 0.01822 & $\chi$ & 0.00637 & $\Delta$ & 0.00008 & $\varepsilon$ & 0.01187 \\
$\phi$ & 0.01941 & $\gamma$ & 0.00004 & $\eta$ & 0.02873 & $\varphi$ & 0.00010 & $\kappa$ & 0.06160 \\
\hline
\end{tabular}

Only two parameters are continuous parameters: $V_{\mathrm{c}}$ (cutting speed) and $f$ (feed rate). The representation in two dimensions is thus possible.

Each combination of discrete parameters $N$ (insert type), $R_{\varepsilon}$ (nose radius), and $M$ (material) corresponds to an $f_{i}$ function. The map of dispersions obtained for the combination $N R_{\varepsilon} M=(-1-1-1)$ is represented by Figure 5. It is a representation in two dimensions where the grey areas correspond to the range of variation of the $\Delta R_{\mathrm{u}}$ response.

\subsubsection{CRITERIA OF USE FOR THE $\Delta R_{u}$ KNOW-HOW MAP}

For each combination of discrete parameters $N R_{\varepsilon} M$, we observe that the regression Equation (1) is:

$$
\Delta R_{\mathrm{u}}=C_{1}+\alpha_{1} x_{1}+\beta_{1} x_{2}
$$

$C_{1}, \alpha_{1}$, and $\beta_{1}$ are constants and $x_{1}$ and $x_{2}$ are the continuous parameters $V_{\mathrm{c}}$ and $f$.

The regression Equation (1) is a datum plane equation. The two main areas of dispersions are a '0.02-0.04' area and a '0.04-0.06' area. The border between the two areas is the place where $\Delta R_{\mathrm{u}}$ is equal to 0.04. Equation (1) then becomes: $0.004=$ $C 1+\alpha_{1} x_{1}+\beta_{1} x_{2}$, which is a straight line equation (Figure 5). Thus, it is considered that the points located close to and on the common line are included in the third zone of dispersions ' 0.04 ' whose amplitude is defined by the expert. 
Table 5. Synthesis of the parameters influence.

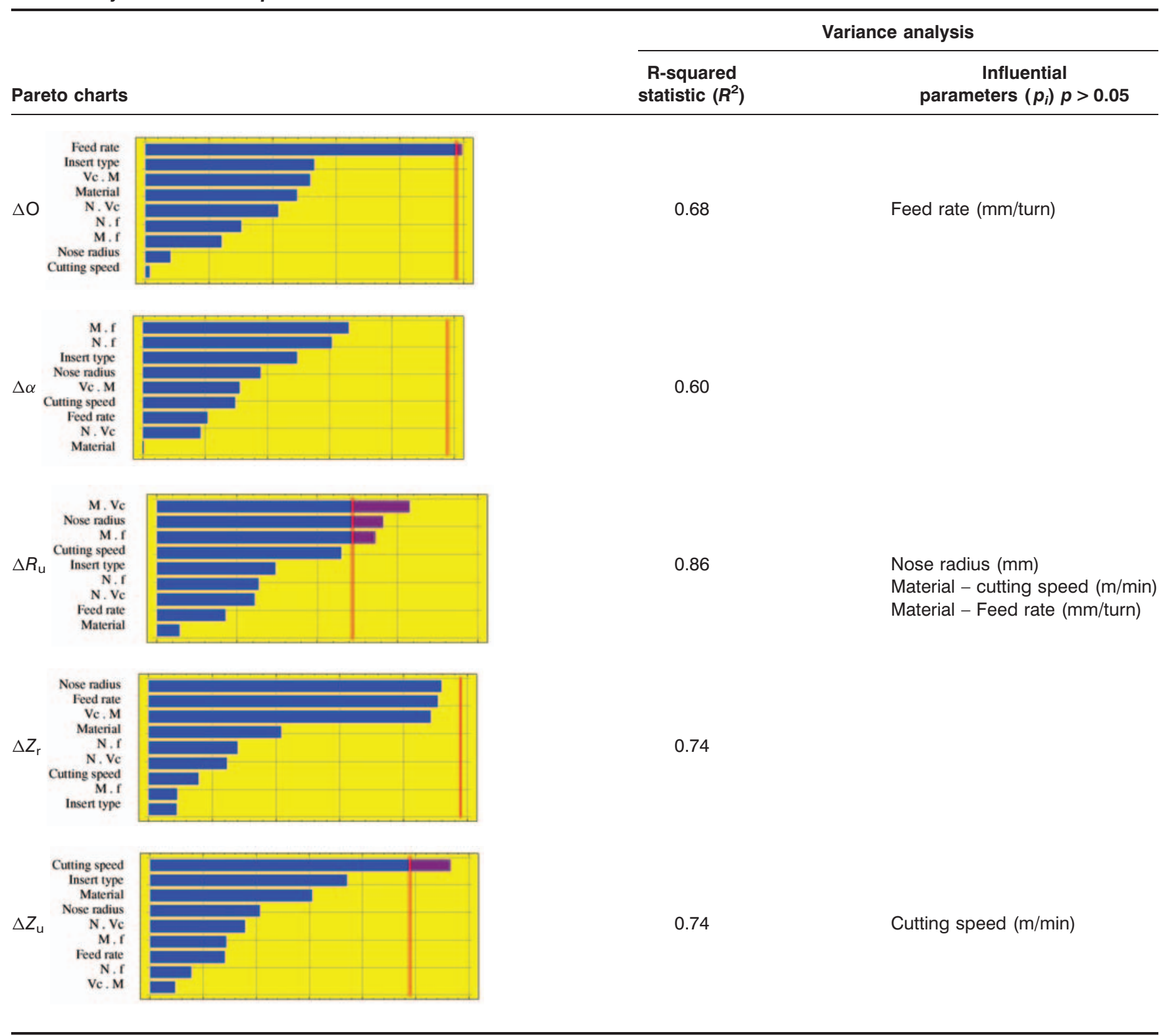

$\underline{\text { Radial dispersions }}$

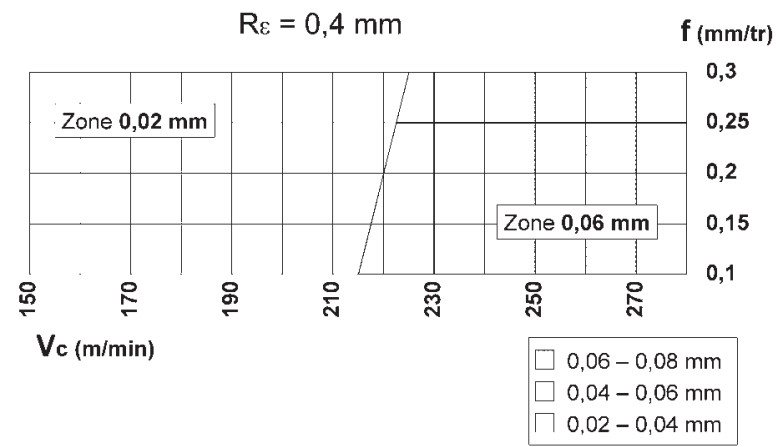

Figure 5. Map of dispersions for ' $\mathrm{P} 15$ ' tool insert type, a $0.4 \mathrm{~mm}$ nose radius and $\mathrm{A} 60$ material.
When the amplitude of the interval in which the response varies is higher or equal to 0.01 , the value of the smallest hundredth millimeter included in this interval is retained. For example, as shown in Figure 6, the amplitude of the variation interval is: $0.06-0.02=0.04>0.01$. Thus two ranges of response are identified: a '0.02-0.04' range and a '0.04-0.06' range. For the first range, the selected dispersion will be $0.02 \mathrm{~mm}$ and for the second range, the selected dispersion will be $0.04 \mathrm{~mm}$.

Three areas will be defined by the expert: for the first, the dispersion selected will be $0.02 \mathrm{~mm}$; for the second, the dispersion selected will be $0.04 \mathrm{~mm}$; and for the third, dispersion will be $0.06 \mathrm{~mm}$ (Figure 6). 


\section{Using Know-how Maps}

A simple application to illustrate the use of the dispersions model in the approach of know-how maps is presented here.

The aim of this study is to select the best parameters to optimize the process plan. Continuing the example of the $\Delta R_{\mathrm{u}}$, which corresponds to the machining dispersions according to $\mathrm{X}$-axis (Section 3.5), Figure 7 shows the $\Delta R_{\mathrm{u}}$ values for two cutting parameters $\left(V_{\mathrm{c}}, f\right)$. These parameters are statistically significant parameters that have been highlighted by the design of experiments (Section 3.4.2).

The process planner must choose $V_{\mathrm{c}}$ according to the roughness and specified tolerances. Roughness allows a range of the feed rate $(f)$ for each $R_{\varepsilon}$ value. The knowhow map provides the possibility of finding the higher value for $V_{\mathrm{c}}$, which corresponds to an economical criterion regarding the dimensioning tolerances.

The maximal feed rate $f$ is $0.15 \mathrm{~mm} /$ turn for a roughness $R_{\mathrm{a}}$ equal to $1.6 \mu \mathrm{m}$ on a turned workpiece

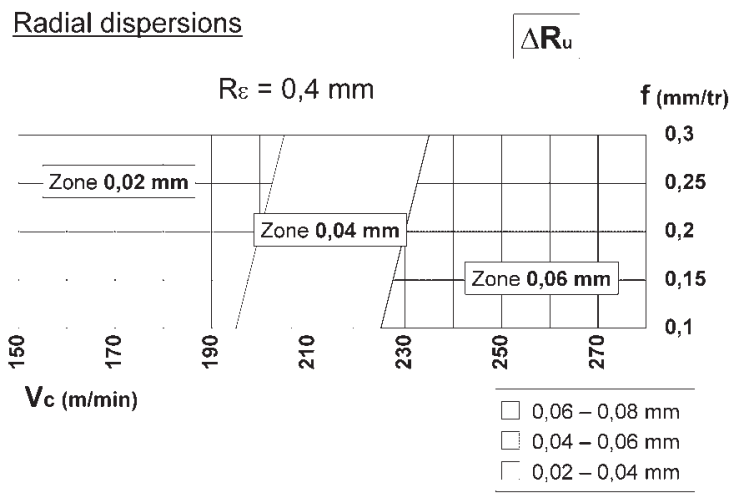

Figure 6. Definition of the various areas of know-how. with $R_{\varepsilon}$ equal to $0.4 \mathrm{~mm}$ (Sandvik documentation). As shown on Figure 7 dispersions increase with the cutting speed $V_{\mathrm{c}}$. Then for a turned diameter $\varnothing 50 \mathrm{H} 8$, the maximum cutting speed allowed in respect of the dimensioning tolerances is equal to $200 \mathrm{~m} / \mathrm{min}$ (Figure 6).

\section{Conclusion}

One of the key facts of the knowledge capitalization process is the expert know-how reuse for new product development in an innovation context.

In this article several methods used in the industry are presented and a new approach which consists of knowledge modeling by a know-how map is proposed. These maps are 2D graphical representations of experts' knowledge and are associated with technical recommendations. The main advantages of these 'ready to use maps' are the time decrease in design and manufacturing processes and the optimization of manufacturing parameters.

The control of the manufacturing dispersions promotes the decrease of the gap between the functional 'target' product and the real manufactured product. Moreover, the control operations allow one to quantify it. The approach developed in this article aims at spreading the classic dispersion model by taking into account the geometrical specifications of orientation and position. Moreover, the formalization of information exchanged between the design and manufacturing offices is one of the key factors for the decrease in time necessary to design a product.

The know-how maps allow the experts to take into account the influence of variations in manufacturing

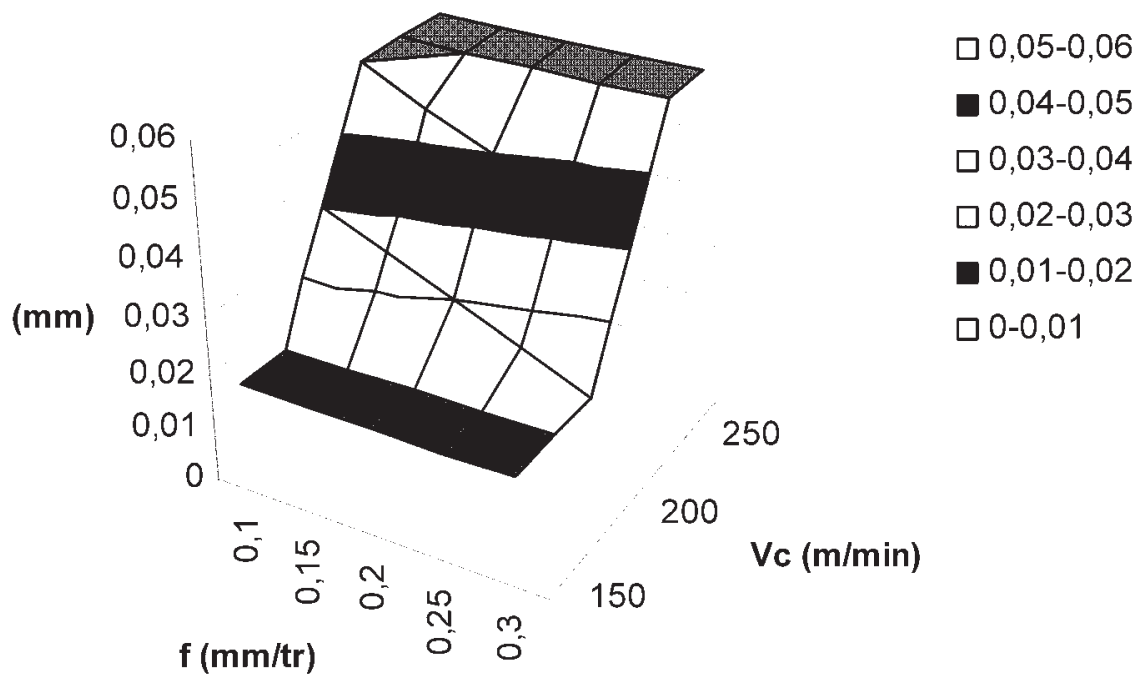

Figure 7. Dispersion evolution for $R_{\varepsilon}=0.4 \mathrm{~mm}$. 
parameters (cutting parameters and equipment used) on machining dispersions. In addition to the predictive aspect, the user has the possibility to see capitalized know-how on the map and thus he can better consider the capability of real machine-tools according to the studied process.

\section{References}

1. Houdoy, H. (1999). Pilotage et évaluation des processus de conception, L'Harmattan, pp. 69-87.

2. Renaud, J. (2002). Amélioration du processus de conception par capitalization des connaissances métier dans un contexte d'Ingénierie Concourante, Habilitation à Diriger des Recherches.

3. Anselmetti, B. and Villeneuve, F. (1992). Computer Aided Process Planning: Two Ways for Including a User's Knowhow', In: Proceedings of the CIRP Seminars, Manufacturing Systems: 23rd Int. CIRP Conference on Production Systems, NANCY, Juin 1991, CIRP Annals, Vol. 21, no. 3, pp. 167-172.

4. Polanyi, M. (1967). The Tacit Dimension, Routlege and Kegan Paul, Londres.

5. Hershel, R.T., Nemati, H. and Steiger, D. (2001). Tacit to Explicit Knowledge Conversion: Knowledge Exchange Protocols, Journal of Knowledge Management, 5: 107-116.

6. Johannessen, J.A., Olaisen, Olsedn, B. (2001). Mismanagement of Tacit Knowledge: the Important of Tacit Knowledge, the Danger of Information Technology, and What to do About it, International Journal of Information Management, 21: 3-20.

7. Lefebvre, A. (2001). Méthodologie et outil de capitalization des connaissances métier pour l'élaboration de gammes d'usinage: application à l'usinage des culasses automobile, Thèse de doctorat, Université Blaise Pascal Clermont II.

8. Lefebvre, A., Renaud, J., Sabourin, L. and Gogu G. (2001). Formalisation des savoir-faire métier pour la conception des gammes de fabrication série. Application à l'usinage des culasses, Renault, projet IAO-DM, 4ème Congrès International de Génie Industriel, GI 2001, Vol. 1, Aix Marseille, 12-15 juin 2001, pp. 141-151.

9. Pachulski, A., Grunstein, M., Gameth, RosenthalSabroux C. (2000). A Methodology Aimed to Locate the Company's Crucial Knowledge, ECKM 2000, Bled Slovénie, 26-27 October 2000.

10. Drucker, P. (1993). Au delà du capitalisme, la métamorphose de cette fin de siècle, Dunod, Paris, Edition originale "Post-capitalism society», Butterworth-Heinemann Ltd., Oxford, Great Britain.

11. Lewkowicz, M. and Zacklad, M. (2000). A Guide Through the Construction of a Groupware for Efficient Knowledge Management, dans: R. Dieng., A. Giboin, L. Karsenty and G. de Michelis (dir.), Designing Cooperative Systems, Amsterdam IOS Press.

12. Aussenac N., Krivine, J.L. et Sallantin, J. (1992). Editorial: l'acquisition des connaissances pour les systèmes à base de connaissances, Revue d'intelligence artificielle, 6, numéro spécial sur l'acquisition des connaissances, pp. 7-18.

13. Mony, C. (1994). DFM: enjeux, tendances et état de l'art, ADEPA, maison de la productique.
14. De, Terssac G. (1991). Analyse du travail et qualification, pp. 295-315, in Modèles en analyse du travail, Amalberti/ de Montmollin/Theureau, Pierre Mardaga Editeur, 1991.

15. Tollenaere, M. (1998). Conception de produits mécaniques, Editions Hermès, Paris, ISBN 2-86601-694-7.

16. Ermine, J.L. (1996). Les systèmes de connaissances, Collection Hermès.

17. Steels, L. (1987). The Deepening of Expert Systems, AICOM, 1: 9-16.

18. Steels, L. (1993). Corporate knowledge Management, In: Proceedings of the International Symposium on the Management of Industrial and Corporate Knowledge (ISMICK'93), Compiègne, pp. 9-30.

19. Vranes, S. and Stanojevic, M. (2000). Design Knowledge Representation in Prolog/Rex. Engineering Applications of artificial Intelligence, 12: 221-228.

20. Corbel, J.C. (1997). Méthodologie de retour d'expérience: démarche MEREX de Renault, connaissances et savoirfaire en entreprise, Hermès.

21. Brown, S. (1992). Cognitive Mapping and Repertory Grids for Qualitative Survey Research: Some Comparative Observations, Journal of Management Studies, 29: 287-308.

22. Heider, F. (1971). Attitudes et organisation cognitive, In Faucheux, Psychologie sociale théorique et expérimentale, Journal of Psychology, Vol. 21, Paris Mouton.

23. Kelly, G.A. (1955). The Psychology of Personal Constructs, New York: Norton.

24. Verstraete, T. (1996). Cartographie cognitive et accompagnement de projet de création d'entreprise, cahier de recherche du CLAREE, Lille.

25. Eden, C. (2003). Analysing Cognitive Maps to Help Structure Issues or Problems, European Journal of Operational Research.

26. Eden, C. (1988). Cognitive Mapping: A Review, European Journal Operational Research, 36: 1613.

27. Langfield-Smith, K.M. (1992). Exploring the Need for a Shared Cognitive Map, Journal of Management Studies, 29(3): 349-368.

28. Woo, J.H., Clayton, M.J., Johnson, R.E., Flores, B.E. and Ellis, C. (2004). Dynamic Knowledge Map: Reusing Expert' Tacit Knowledge in the AEC Industry, Automation in Construction, 13: 203-207.

29. Alengry, P. (1988). Connaissances profondes et connaissances de surface dans la modélisation du raisonnement, Revue de Psychologie Française, Vol. 33-3, pp. 171-176.

30. Shanteau, J., Weiss, D.J., Thomas, R.P. and Pounds, J.C. (2002). Performance-based Assessment of Expertise: How to Decide if Someone is an Expert or Not, European Journal of Operational Research, 136: 253-263.

31. Cossette P. (1994). Cartes cognitives et organisations, Presses de l'Université, Laval, Editions Eska.

32. Cossette, P. and Audet, M. (1992). Mapping of Idiosyncratic Schema, Journal of Management Studies, 29: 325-348.

33. Voirpin, J.-M., Renaud, J., Dufour, M., Mutel, B. and Guidat, C. (1998). Design Rules, a Method for the Modeling of Technical Data in the Context of Innovation, INCOM 98, Nancy.

34. Anselmetti, B. (2003). Cotation de fabrication et métrologie, Volume 3, Editions Hermès, Avril 2003.

35. Scheider, F. and Martin, P. (1999). Réglage optimal des machines outils, Technologie et Formation, no. 86: 56-59. 
36. Pillet, M. (1996). Appliquer la maîtrise statistique des procédés MSP/SPC, Les éditions d'organisation, 1996

37. Wolff, V. (2000). Le suivi de la cotation des pièces fabriquées pour la conception coopérante en mécanique, Thèse de doctorat, INSA de Lyon.

38. Goupy, J. (1988). La méthode des plans d'expériences Optimisation du choix des essais et de l'interprétation des résultats, Editions Dunod/Bordas.

39. Vigier, M. (1988). Pratique des plans d'expériences (Méthodologie Taguchi), Les Editions d'Organisation.

40. Pillet, M. and Regnier, G. (1995). Les plans d'expériences: outil de la démarche expérimentale, Institut pour la promotion des Sciences de l'Ingénieur, Paris, 1995.

41. Dessein, G., Redonnet, J.-M., Lagarrigue, P. and Rubio, W. (1998). Correction des trajectoires d'une machine outil à commande numérique par une qualification des dispersions selon l'usinage, IDMME'98, In: 2ème conférence internationale sur la conception et la fabrication, Compiègne, pp. 759, 27-29 Mai 1998.

\section{Valéry Wolff}

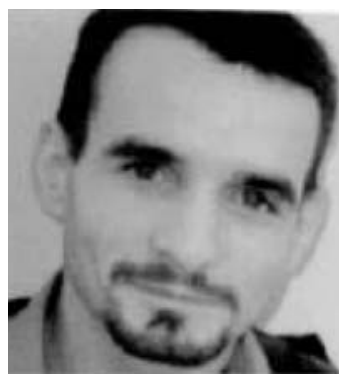

Valéry Wolff is a lecturer at Claude Bernard University, in the Mechanical and Production Department. His research focuses on the manufacturing processes in a concurrent engineering context and more precisely on machining dispersion problems. He received a $\mathrm{PhD}$ degree in Mechanical Engineering from INSA of Lyon.

\section{Dr Arnaud Lefebvre}

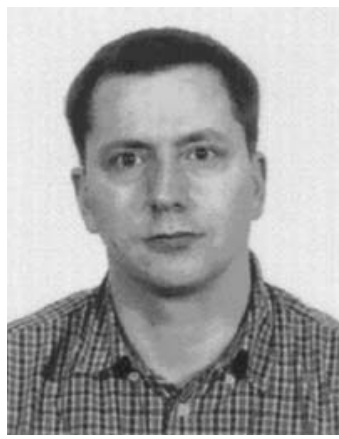

Dr Arnaud Lefebvre is an assistant professor of Mechanical Engineering at Claude Bernard University in Lyon. His research focuses on knowledge capitalization as applied to the manufacturing industry. One of the main aspects concerns the possibility of reusing this knowledge and structuring the design modeling of mass-production plans. He received a BEng. Honours in Engineering with Management from Napier University and a $\mathrm{PhD}$ degree in Mechanical Engineering from Blaise Pascal University.

\section{Jean Renaud}

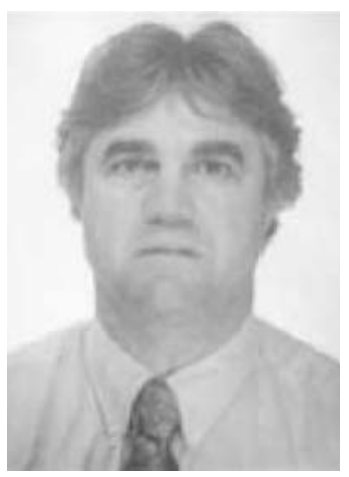

Jean Renaud is an assistant professor of innovation at the Ecole Nationale Supérieure en Génie des Systèmes Industriels of Nancy, France. He holds a $\mathrm{PhD}$ degree in Industrial Engineering. His research focuses on concurrent engineering and multicriteria analysis. Renaud currently serves as innovation expert in French firms and heads a national association on project management. 